DOI: $10.5216 /$ cab.v12i1.12229

\title{
DESEMPENHO E CARCACTERÍSTICAS DE CARCAÇA DE NOVILHAS CRUZADAS DE TRÊS GRUPOS GENÉTICOS RECEBENDO DIETAS À BASE DE SILAGEM DE SORGO E MILHO
}

\author{
Wagner Azis Araújo, ${ }^{1}$ Pedro Veiga Paulino, ${ }^{2}$ Marcos Inácio Marcondes, ${ }^{3}$ \\ Carlos Guilherme Vasconcelos Carvalho ${ }^{4}$ e Francisco Carlos de Oliveira Silva ${ }^{5}$
}

\begin{abstract}
1. Doutorando em Nutrição e Produção de Monogástricos na Universidade Federal de Viçosa. E-mail: aziszoo@yahoo.com.br 2. Professor Adjunto da Universidade Federal de Viçosa

3. Professor Adjunto I da Universidade Federal de Viçosa

4. Professor/pesquisador da Empresa de Pesquisa Agropecuária de Minas Gerais

5. Pesquisador da Empresa de Pesquisa Agropecuária de Minas Gerais.
\end{abstract}

RESUMO

Buscou-se com o presente trabalho avaliar a qualidade da carcaça e o ganho de peso de novilhas cruzadas de três grupos genéticos, alimentadas com silagem de milho ou de sorgo. Foram utilizadas dezoito novilhas filhas de vacas meio-sangue (Holandês $\mathrm{x}$ Gir), sendo seis oriundas de cruzamentos com touros da raça Gir (TGG: 3/4 Gir e 1/4 Holandês), seis com touros da raça Nelore (TNG: $1 / 2$ Nelore, $1 / 4$ Gir e $1 / 4$ Holandês), e seis com touros da raça Guzerá (TUG: $1 / 2$ Guzerá, $1 / 4$ Gir e $1 / 4$ Holandês). Os animais foram distribuídos em um esquema fatorial ( $3 \times 2$ ), formando três grupos genéticos. Estimaram-se o ganho de peso diário, o consumo e a conversão alimentar. No início e no fim do experimento foram aferidas a área de olho de lombo (AOL) e a espessura de gordura subcutânea entre a $12^{\mathrm{a}}$ e a $13^{\mathrm{a}}$ costelas (EGSUB), além da espessura de gordura sobre o músculo Biceps femoris (EGPUB), por meio de ultrassom. Não houve influência do grupo genético sobre as variáveis avaliadas. A silagem de milho proporcionou maior desempenho em relação à silagem de sorgo.

PALAVRAS-CHAVES: Animais cruzados, fração volumosa da dieta, ganho de peso, qualidade da carcaça.

\section{ABSTRACT}

\section{PERFORMANCE AND CARCASS TRAITS OF CROSSBRED HEIFERS FROM THREE GENETIC GROUPS FED CORN OR SORGHUM SILAGE BASED DIETS}

This study aimed to evaluate the carcass quality and the weight gain of crossbred heifers from three genetic groups, fed corn or sorghum silage. Eighteen heifers, 6 originated from crossbreds between $1 / 2$ Holstein/Gir cows and Gir bulls (TGG: 3/4 Gir and $1 / 4$ Holstein), six from crossbreds between $1 / 2$ Holstein/Gir cows and Nellore bulls (TNG: $1 / 2$ Nellore, $1 / 4$ Gir and $1 / 4$ Holstein), and six from crossbreds between $1 / 2$ Holstein/Gir cows and Guzera bulls (TUG: $1 / 2$ Guzera, $1 / 4$ Gir and $1 / 4$ Holstein). The animals were distributed in a completely randomized design, in a $3 \times 2$ factorial arrangement, with three genetic groups. Daily weight gain, intake, and feed conversion were estimated. At the beginning and end of the experiment, the ribeye area (REA), the subcutaneous fat between $12^{\text {th }}$ and $13^{\text {th }}$ ribs (SFBR), and the subcutaneous fat under the Biceps femoris muscle (SFBFM) were obtained by ultrasound. The genetic groups did not influence the variables evaluated. Corn silage diets provided a higher performance than the sorghum silage diets.

KEYWORDS: Carcass quality, crossbred animals, roughage fraction of the diet, weight gain. 


\section{INTRODUÇÃO}

Em sistemas brasileiros de criação de bovinos de duplo propósito é frequente o cruzamento de vacas meio-sangue (Holandês x Zebu) com touros zebuínos (Bos taurus indicus), originando cruzamento terminal, destinando os machos e as fêmeas para a produção de carne. A criação desses animais é onerosa, pois eles ocupam pastagens destinadas às vacas em lactação. É desejável que a permanência desses bovinos na fazenda, seja a menor possível e que deles se façam produtores especializados em recria e terminação.

Estima-se que $65 \%$ do rebanho bovino do estado de Minas Gerais é explorado com dupla finalidade, e observa-se que os bezerros provenientes de rebanhos leiteiros são utilizados para recria e engorda como bovinos de corte (PAULINO et al., 2006).

Poucas pesquisas brasileiras comparam fêmeas de descarte para produção de carne (RESTLE et al., 2001), sendo que a grande maioria utiliza vacas em final de produção (KUSS et al., 2005). Porém, atualmente é elevado o número de fêmeas jovens abatidas nos frigoríficos, sobretudo aquelas oriundas de cruzamentos com raças zebuínas de corte. Algumas das raças zebuínas mais difundidas no Brasil são a Nelore, a Gir e a Guzerá. Portanto é comum, e de baixo custo, a aquisição de touros dessas raças. Segundo ROCHA JR. et al. (2010), há bastante semelhança na característica de ganho de peso entre esses animais mestiços e os de raças zebuínas de corte puras, quando em confinamento. Assim seria viável o confinamento de animais oriundos do cruzamento de rebanhos leiteiros meio-sangue com raças de corte zebuínas.

As silagens de milho (Zeas mays L.) e de sorgo (Sorghum vulgare Pers.) são bastante utilizadas em sistemas de confinamento de bovinos de corte. Segundo PIMENTEL et al. (1998), o valor nutritivo da silagem de milho é considerado superior ao da silagem de sorgo. Em termos médios, a silagem de sorgo apresenta coeficientes de digestibilidade aparente da matéria seca (MS), da proteína bruta (PB) e da energia bruta (EB) inferiores, possuindo entre $85,0 \%$ e $92,0 \%$ do valor nutritivo da silagem de milho. Entretanto, para a terminação em confinamento, a silagem de sorgo vem despertando a preferência dos produtores, por apresentar alta produtividade da lavoura e menor sensibilidade a períodos curtos de estiagem (NEUMANN et al., 2002).

$\mathrm{Na}$ elaboração de um plano nutricional para bovinos de corte, é necessário almejar carcaças com alta proporção de músculos e adequada quantidade de gordura (GESUALDI JR. et al., 2006). O estudo das características da carcaça tem importância quando o objetivo é avaliar a qualidade do produto final do sistema de produção de bovinos de corte. TAROUCO et al. (2005), confirmaram o potencial de predição por ultrassonografia em animais vivos. Segundo BASARAB et al. (1999), várias estratégias de classificação de animais em confinamento, conduzidas entre três e seis meses antes do abate, têm mostrado potencial para melhorar a uniformidade de carcaça e o lucro dos bovinos para o abate.

Assim, estudos sobre esses aspectos norteiam os produtores leiteiros na escolha da raça de Bos taurus indicus mais recomendada para o cruzamento, com a finalidade de produzir novilhos mais precoces, pesados e com melhor acabamento de carcaça. Os estudos ainda buscam apontar a silagem mais apropriada para o confinamento. Com base nisso, objetivouse neste trabalho avaliar a qualidade da carcaça e o desempenho de novilhas cruzadas (Nelore, Gir e Guzerá), alimentadas com silagem de milho ou silagem de sorgo.

\section{MATERIAL E MÉTODOS}

O estudo foi desenvolvido na fazenda experimental pertencente à Empresa de Pesquisa Agropecuária de Minas Gerais (EPAMIG), no município de Pitangui, MG, no período de maio a agosto de 2009. Foram utilizadas dezoito novilhas, filhas de vacas meio-sangue ( $1 / 2$ Holandês e $1 / 2 \mathrm{Gir})$, pesando $202 \pm 17 \mathrm{~kg}$, sendo seis oriundas de cruzamentos com touros da raça Gir (TGG: 3/4 Gir e 1/4 Holandês), seis com touros da raça Nelore (TNG: $1 / 2$ Nelore, $1 / 4$ Gir e $1 / 4$ Holandês), e seis com touros da raça Guzerá (TUG: $1 / 2$ Guzerá, 1/4 Gir e 1/4 Holandês). As novilhas foram identificadas com brincos plásticos e marcação a ferro e mantidas em currais de confinamento, recebendo sal mineral comercial à vontade, em cochos cobertos, e água ad libitum, em bebedouros plásticos.

Dividiram-se os animais em esquema fatorial ( $3 \times 2$ ), formando três grupos genéticos que foram 
alimentados com dois volumosos diferentes à base de milho (Zeas mays L.) e de sorgo (Sorghum vulgare Pers.), com três repetições. As melhoras foram pesadas, vermifugadas e distribuídas aleatoriamente em baias individuais, com área total de $10 \mathrm{~m}^{2}$. Elas receberam dietas isoproteicas e isoenergéticas, balanceadas para conterem aproximadamente $14,5 \%$ de proteína bruta e $70,0 \%$ de nutrientes digestíveis totais (NDT), com relação volumoso:concentrado de 60:40, com base na matéria seca (Tabela 1). As exigências nutricionais seguiram o preconizado por NRC (2001) para novilhas em recria.

TABELA 1. Dieta oferecida aos animais durante o período experimental (em \% com base na matéria seca), e seus conteúdos em proteína bruta (PB), nutrientes digestíveis totais (NDT), fibra em detergente neutro (FDN) e extrato etéreo (EE)

\begin{tabular}{lcc}
\hline Alimento & $\begin{array}{c}\text { Silagem de } \\
\text { milho }\end{array}$ & $\begin{array}{c}\text { Silagem de } \\
\text { sorgo }\end{array}$ \\
\hline Silagem de milho (\%) & 60,00 & 0,00 \\
Silagem de sorgo (\%) & 0,00 & 60,00 \\
Milho (grão) (\%) & 30,70 & 26,00 \\
Farelo de soja (\%) & 7,00 & 8,00 \\
Óleo de soja (\%) & 0,00 & 3,50 \\
Ureia (\%) & 1,05 & 1,15 \\
Sulfato de amônio (\%) & 0,15 & 0,20 \\
Suplemento mineral ${ }^{1}(\%)$ & 1,10 & 1,15 \\
Conteúdo nutricional (\% na MS) & & \\
NDT & 70,00 & 70,00 \\
PB & 14,50 & 14,50 \\
FDN & 38,79 & 38,47 \\
EE & 2,97 & 6,31 \\
\hline
\end{tabular}

${ }^{1}$ Composição centesimal para a dieta de silagem de milho: calcário - 53,5\%, fosfato bicálcico $-29,0 \%$, cloreto de sódio $-12,0 \%$, flor de enxofre $-5,7 \%$, sulfato de cobre $-0,10 \%$, sulfato de zinco $-0,65 \%$, iodato de potássio $0,004 \%$, sulfato de cobalto $-0,0015 \%$, selenito de sódio $-0,002 \%$ e veículo qsp; e para a de silagem de sorgo: calcário - 50,0\%, fosfato bicálcico $32,5 \%$, cloreto de sódio $-11,5 \%$, flor de enxofre $-5,5 \%$, sulfato de cobre $-0,10 \%$, sulfato de zinco $-0,7 \%$, iodato de potássio $-0,0041 \%$, sulfato de cobalto $-0,0015 \%$, selenito de sódio $-0,002 \%$ e veículo qsp.

O experimento teve duração de 99 dias (quinze para adaptação dos animais às dietas e 84 dias experimentais), divididos em três períodos de 28 dias. Após o período de adaptação, e jejum de quatorze horas, realizaram-se as pesagens dos animais para determinação do ganho de peso médio diário (GMD), consumo médio diário (CMD) e conversão alimentar (CA) para os períodos distintos (1, 2 e 3) e para o período total, respectivamente GMDT, CMDT e CAT. A alimentação foi fornecida à vontade, em duas refeições diárias, às 7 e às 15 horas.

No início e ao final do experimento foram aferidas a área de olho de lombo (AOL) (área do músculo Longissimus dorsi, $\mathrm{cm}^{2}$ ) e a espessura de gordura subcutânea entre a $12^{\mathrm{a}}$ e a $13^{\mathrm{a}}$ costelas (EGSUB), além da espessura de gordura sobre o músculo Biceps femoris (EGPUB), por meio de ultrassom. Para obtenção das imagens de ultrassom, utilizou-se um equipamento Piemedical, modelo Scanner 200 VET, com transdutor de arranjo linear, frequência de $3.5 \mathrm{MHz}$ e $178 \mathrm{~mm}$ de comprimento, com guia acústica acoplada para melhor adaptação à anatomia do animal. As imagens obtidas foram gravadas em microcomputador acoplado ao ultrassom para posterior análise, por intermédio do programa computacional EView ${ }^{\circledR}$ (Piemedical Inc.).

Os dados foram submetidos às análises de covariância e teste de Tukey pelo software SAS ${ }^{\circledR}$ (SAS 2002). O peso inicial dos animais foi considerado covariável. Foi utilizado $10 \%$ como nível crítico de significância para verificação de diferenças entre tratamentos.

\section{RESULTADOS E DISCUSSÃO}

A interação entre dieta e grupo genético foi não significativa para GMD, AOL e EGPUB $(\mathrm{P}>0,10)$, sendo, portanto, os fatores analisados separadamente para essas variáveis.

Não observaram diferenças significativas $(\mathrm{P}>0,10)$ entre os grupos genéticos avaliados (Tabela 2). ROCHA JR. et al. (2010) também não identificaram diferenças no ganho de peso de animais mestiços Holandês Zebu. Há uma proximidade grande das raças estudadas, pois todas são zebuínas, e, apesar da diferença nos programas de melhoramento genéticos, a baixa variabilidade entre essas raças provavelmente proporciona desempenhos semelhantes. A partir daí, infere-se que se podem usar touros de qualquer das três raças estudadas, pois as novilhas possuirão desempenho similar. 
TABELA 2. Análise bromatológica das silagens de milho e sorgo

\begin{tabular}{|c|c|c|c|c|c|c|}
\hline Composição bromatológica ${ }^{1}$ & $\begin{array}{l}\text { Silagem de } \\
\text { milho }\end{array}$ & $\begin{array}{l}\text { Silagem de } \\
\quad \text { sorgo }\end{array}$ & Milho & $\begin{array}{l}\text { Farelo de } \\
\text { soja }\end{array}$ & Ureia & $\begin{array}{c}\text { Sulfato de } \\
\text { amônio }\end{array}$ \\
\hline Matéria seca (em \%) & 27,40 & 29,90 & 90,35 & 89,86 & 98,85 & 99,10 \\
\hline Proteína bruta (em \%) & 8,03 & 6,60 & 42,10 & 9,00 & 281,00 & 129,38 \\
\hline Extrato etéreo (em \%) & 2,92 & 3,00 & 20,00 & 3,70 & - & - \\
\hline Fibra em detergente neutro (em \%) & 59,10 & 68,00 & 14,90 & 9,00 & - & - \\
\hline Fibra em detergente ácido (em \%) & 25,94 & 35,77 & 4,08 & 9,86 & - & - \\
\hline Matéria mineral (em \%) & 4,73 & 5,40 & 1,53 & 6,24 & - & - \\
\hline Cálcio (em \%) & 0,52 & 0,35 & 0,28 & 0,02 & - & - \\
\hline Fósforo (em \%) & 0,16 & 0,21 & 0,66 & 0,31 & - & - \\
\hline
\end{tabular}

${ }^{1}$ Análises realizadas no laboratório de bromatologia do Departamento de Zootecnia da Universidade Federal de Viçosa.

TABELA 3. Ganho de peso médio diário (GMD, em kg) nos períodos e durante todo o experimento (GMDT, em kg), para os grupos genéticos e dietas avaliadas

\begin{tabular}{lcccc}
\hline \multirow{2}{*}{ Itens } & GMD1 & GMD2 & GMD3 & GMDT \\
\cline { 2 - 5 } Guzerá (1/2 Guzerá, 1/4 Gir e 1/4 Holandês) & \multicolumn{3}{c}{ Grupo genético } \\
Gir (3/4 Gir e 1/4 Holandês) & 0,984 & 1,292 & 1,415 & 1,123 \\
Nelore (1/2 Nelore, 1/4 Gir e 1/4 Holandês) & 0,829 & 1,019 & 1,149 & 0,999 \\
\hline & 0,726 & 0,928 & \multicolumn{2}{c}{ Dieta } \\
\hline Silagem de milho & $0,856 \mathrm{a}$ & 1,103 & $1,312 \mathrm{a}$ & $1,141 \mathrm{a}$ \\
Silagem de sorgo & $0,692 \mathrm{~b}$ & $0,976 \mathrm{~b}$ & $0,993 \mathrm{~b}$ & $0,887 \mathrm{~b}$ \\
Coeficiente de variação (\%) & 32,06 & 27,06 & 25,49 & 29,49 \\
\hline
\end{tabular}

Médias seguidas de letras distintas na colunas diferem significativamente pelo teste de Tukey $(\mathrm{P}<0,10)$.

Os animais alimentados com a silagem de milho tiveram desempenho $28,63 \%$ superior $(\mathrm{P}<0,10)$ ao daqueles alimentados com silagem de sorgo (Tabela 3 ). De acordo com VALADARES FILHO et al. (2006), a silagem de milho tem um teor de nutrientes digestíveis totais $12,0 \%$ superior ao da silagem de sorgo, além de possuir digestibilidade da proteína bruta $33,54 \%$ maior. Portanto, é possível que os animais alimentados com silagem de milho tenham recebido uma dieta mais energética e com maior teor de proteína metabolizável, mesmo que ambas as dietas tenham sido formuladas para conterem $14,5 \%$ de PB na matéria seca total.

O uso de óleo em rações para ruminantes apresenta efeitos desejáveis, como inibição da produção de metano, redução da concentração de $\mathrm{NH}_{3}$ ruminal e aumento na eficiência da síntese microbiana. Contudo, o óleo apresenta também efeitos indesejáveis, como redução na digestibilidade da matéria seca (MS) e redução na produção de ácidos graxos voláteis, principalmente o acetato (VARGAS et al., 2002). Talvez por isso a correção da energia utilizando o óleo de soja não tenha sido eficiente, devido às suas propriedades inibidoras da fermentação ruminal e diminuição da digestibilidade da matéria seca.

Ao estudarem o desempenho de animais Nelore, Nelore x Guzerá e Nelore x Brahman, RIBEIRO et al. (2008) não observaram diferenças entre eles quanto ao GMD. Os autores sugerem que a proximidade genética contribuiu para diminuir o efeito de heterose dos animais cruzados, provocando desempenhos semelhantes.

Neste estudo, não foi constatada influência do grupo genético dos animais no consumo de matéria seca $(\mathrm{P}>0,10)$, como mostra a Tabela 4 . A partir do segundo 
período de avaliação, houve maior consumo da dieta à base de silagem de milho que da dieta à base de sorgo $(\mathrm{P}<0,10)$. Durante todo o período, os animais que foram alimentados com silagem de milho consumiram 4,9\% mais matéria seca que os alimentados com silagem de sorgo. Esse consumo mais elevado resultou num maior ganho de peso dos animais alimentados com dieta à base de silagem de milho (Tabela 3 ).

TABELA 4. Consumo médio diário de matéria seca (CMD, em kg) durante os períodos e durante todo o experimento (CMDT), para os grupos genéticos e dietas avaliadas

\begin{tabular}{|c|c|c|c|c|}
\hline \multirow{2}{*}{ Itens } & CMD1 & CMD2 & CMD3 & CMDT \\
\hline & \multicolumn{4}{|c|}{ Grupo genético } \\
\hline Guzerá (1/2 Guzerá, 1/4 Gir e 1/4 Holandês) & 5,6 & 5,7 & 6,5 & 5,9 \\
\hline Gir (3/4 Gir e 1/4 Holandês) & 4,9 & 5,9 & 6,2 & 5,7 \\
\hline \multirow[t]{2}{*}{ Nelore (1/2 Nelore, $1 / 4$ Gir e 1/4 Holandês) } & 5,2 & 5,6 & 6,3 & 5,7 \\
\hline & \multicolumn{4}{|c|}{ Dieta } \\
\hline Silagem de milho & 5,4 & $6,0 \mathrm{a}$ & $6,5 \mathrm{a}$ & $6,0 \mathrm{a}$ \\
\hline Silagem de sorgo & 5,3 & $5,6 b$ & $6,1 b$ & $5,7 \mathrm{~b}$ \\
\hline Coeficiente de variação (\%) & 15,56 & 13,47 & 12,65 & 14,56 \\
\hline
\end{tabular}

Médias seguidas de letras distintas na coluna diferem significativamente pelo teste de Tukey $(\mathrm{P}<0,10)$.

TABELA 5. Conversão alimentar (CA, em $\mathrm{kg} / \mathrm{kg}$ ) durante os períodos e durante todo o experimento (CAT), para os grupos genéticos e dietas avaliadas

\begin{tabular}{|c|c|c|c|c|}
\hline \multirow{2}{*}{ Itens } & CA1 & $\mathrm{CA} 2$ & $\mathrm{CA} 3$ & CAT \\
\hline & \multicolumn{4}{|c|}{ Grupo genético } \\
\hline Guzerá ( $1 \frac{1}{2}$ Guzerá, $1 / 4$ Gir e $1 / 4$ Holandês) & 4,6 & 5,8 & 5,0 & 4,2 \\
\hline Gir (3/4 Gir e 1/4 Holandês) & 4,9 & 7,1 & 6,1 & 4,9 \\
\hline \multirow[t]{2}{*}{ Nelore (1/2 Nelore, 1/4 Gir e 1/4 Holandês) } & 5,7 & 7,7 & 6,8 & 5,2 \\
\hline & \multicolumn{4}{|c|}{ Dieta } \\
\hline Silagem de milho & 4,7 & 7,0 & 5,2 & 4,5 \\
\hline Silagem de sorgo & 6,0 & 8,1 & 6,3 & 5,7 \\
\hline Coeficiente de variação (\%) & 20,36 & 18,53 & 18,06 & 19,03 \\
\hline
\end{tabular}

Médias seguidas de letras distintas na coluna diferem significativamente pelo teste de Tukey $(\mathrm{P}<0,10)$.

A conversão alimentar (CA) também não foi influenciada pelo grupo genético ou pelo tipo de volumoso utilizado. PINTO et al. (2009) verificaram valores semelhantes para a silagem de sorgo ao confinar novilhos machos mestiços inteiros. ROCHA JR. et al. (2010) também reportaram que não houve influência do grupo genético de novilhos mestiços sobre CA e CMD. Portanto, quaisquer dos grupos genéticos, alimentados com silagens de ambos os tipos, apresentam a mesma conversão do alimento em ganho de peso.

A AOL não foi influenciada pelos tratamentos $(\mathrm{P}>0,10)$ como é demonstrado na Tabela 6. A interação entre grupo genético e dieta foi significativa para a EGSUB; entretanto, quando os fatores foram avaliados com grupo genético/dieta e dieta/grupo genético não foi observada influência alguma dos tratamentos sobre 
a EGSUB (P>0,10). PINTO et al. (2009) também não verificaram diferenças nas carcaças de animais mestiços alimentados com diferentes fontes volumosas em sistema de confinamento. Da mesma forma, EUCLIDES FILHO et al. (2001) não encontraram diferenças nas carcaças de animais cruzados de diferentes grupos genéticos.

TABELA 6. Área de olho de lombo (AOL, em $\mathrm{cm}^{2}$ ), espessura de gordura (EGSUB, em cm) entre a $12^{\mathrm{a}}$ e a $13^{\mathrm{a}}$ costelas, e espessura de gordura sobre o músculo Biceps femoris (EGPUB, em $\mathrm{cm}$ ) para os grupos genéticos e dietas avaliadas

\begin{tabular}{|c|c|c|c|}
\hline \multirow{2}{*}{ Itens } & $\mathrm{AOL}$ & EGSUB & EGPUB \\
\hline & \multicolumn{3}{|c|}{ Grupo genético } \\
\hline Guzerá (1/2 Guzerá, $1 / 4$ Gir e $1 / 4$ Holandês $)$ & 39,5 & 2,29 & 3,43 \\
\hline Gir (3/4 Gir e 1/4 Holandês) & 38,3 & 1,82 & 3,35 \\
\hline \multirow[t]{2}{*}{ Nelore (1/2 Nelore, $1 / 4$ Gir e $1 / 4$ Holandês) } & 38,1 & 1,70 & 3,30 \\
\hline & \multicolumn{3}{|c|}{ Dieta } \\
\hline Silagem de milho & 40,0 & 2,06 & 3,87 \\
\hline Silagem de sorgo & 37,3 & 1,81 & 2,85 \\
\hline Coeficiente de variação (\%) & 10,95 & 29,18 & 39,64 \\
\hline
\end{tabular}

Médias seguidas de letras distintas na coluna diferem significativamente pelo teste de Tukey $(\mathrm{P}<0,10)$.

Apesar de os animais alimentados com silagem de milho apresentarem maior ganho de peso, não foi verificada melhoria nas suas carcaças. Os resultados demonstram que não houve superioridade de algum grupo genético quanto às variáveis GMD, $\mathrm{AOL} \mathrm{e}$ EGSUB. Animais de qualquer um dos grupos podem produzir um acabamento de carcaça adequado às exigências do mercado, no qual os cortes mais valorizados economicamente encontram-se nos quartos traseiros dos animais, enfatizando a importância da maior EGPUB. Da mesma forma, pode-se inferir que quaisquer das estratégias de alimentação podem ser utilizadas, se o objetivo do confinamento o rendimento de cortes traseiros. Resta, por último, a decisão de uso destas dietas quanto à análise econômica do sistema de produção.

\section{CONCLUSÃO}

Não há influência do grupo genético sobre as variáveis avaliadas. Dietas à base de silagem de milho proporcionam novilhas mais pesadas, porém com características de carcaça iguais às das novilhas alimentadas com silagem de sorgo.

\section{REFERÊNCIAS}

BASARAB, J. A.; BRETHOUR, J. R.; ZOBELL, D. R. Sorting feeder cattle with a system that integrates ultrasound backfat and marbling estimates with a model that maximizes feedlot profitability in value-based marketing. Canadian Journal of Animal Science, v. 79, n. 3, p. 327-334, 1999.

EUCLIDES FILHO, K.; FEIJÓ, G. L. D.; FIGUEIREDO, G. R.; EUCLIDES, V. P. B.; SILVA, L. O. C.; CUSINATO, V. Q. Efeito de idade à castração e de grupos genéticos sobre o desempenho em confinamento e características de carcaça. Revista Brasileira de Zootecnia, p. 71-76 v. 30, n. 1, 2001.

GESUALDI JR. A.; QUEIROZ, A. C.; RESENDE, F. D.; ALLEONI, G. F.; RAZOOK, A. G.; FIGUEIREDO, L. A.; GESUALDI, A. C. L. S.; DETMANN, E. Características de carcaça de bovinos Nelore e Caracu selecionados para peso aos 378 dias de idade recebendo alimentação restrita ou à vontade. Revista Brasileira de Zootecnia, v. 35, n. 1, p. 131-138, 2006. Disponível em: <http://www.scielo.br/pdf/rbz/v35n1/28352.pdf $>$. Acesso em: 20 mar. 2010.

KUSS, F.; RESTLE, J.; BRONDANI, I. L.; FILHO, D. C. A.; PEROTTONI, J.; MISSIO, R. L.; AMARAL, G. A. Composição física da carcaça e qualidade da carne de vacas de descarte de diferentes grupos genéticos terminadas em confinamento com distintos pesos. Revista Brasileira de Zootecnia, v. 34, n. 4, p. 1.285-1.296, 2005.

NRC - NATIONAL RESEARCH COUNCIL. Nutrient requirements of dairy cattle. 7. ed. Washington: Academic Press, 2001. $381 \mathrm{p}$.

NEUMANN, M.; RESTLE, J.; ALVES FILHO, D. C.; BRONDANI, I. L.; PELLEGRINI, L. G.; FREITAS, A. K. Avaliação do valor 
nutritivo da planta e da silagem de diferentes híbridos de sorgo (Sorghum bicolor, L. Moench). Revista Brasileira de Zootecnia, v. 31, n.1, (supl.) p. 293-301, 2002. Disponível em: <http://www. scielo.br/scielo.php?pid=S1516-35982002000200002\&script $=$ sci arttext>. Acesso em: 25 mar. 2010.

PAULINO, M. F.; MORAES, E. H. B. K.; ZERVOUDAKIS, Z. T.; ALEXANDRINO, E.; FIGUEIREDO, D. M. Terminação de novilhos mestiços leiteiros sob pastejo, no período das águas, recebendo suplementação com soja. Revista Brasileira de Zootecnia, v. 35, n. 1, p. 154-158, 2006.

PIMENTEL, J. J. O.; SILVA, J. F. C.; VALADARES FILHO, S. C.; CECON, P. R.; SANTOS, P. S. Efeito da suplementação protéica no valor nutritivo de silagens de milho e sorgo. Revista Brasileira de Zootecnia, v. 27, n. 5, p. 1.042-1.049, 1998.

PINTO, A. P.; NASCIMENTO, W. G.; ABRAHÃO, J. J. S.; Perotto, D.; MOletTA, J. L.; LUGÃO, S. M. B. Digestibilidade, consumo, desempenho e características de carcaça de tourinhos mestiços confinados com cana-de-açúcar ou silagem de sorgo. Revista Brasileira de Zootecnia, v. 38, n. 11, p. 2.258-2.263, 2009.

RESTLE , J.; CERDÓTE, L.; VAZ, F. N.; BRONDANI, I. L. Características de carcaça e da carne de novilhas charolês e $3 / 4$ charolês $1 / 4$ nelore, terminadas em confinamento. Revista Brasileira de Zootecnia, v. 30, n. 3, (supl.1), p. 1.065-1.075, 2001. Disponível em: $<$ http://www.scielo.br/scielo.php?script=sci_artte xt\&pid=S1516-35982001000400022> . Acesso em: 20 mar. 2010.

RIBEIRO, E. L. A.; HERNANDEZ, J. A.; ZANELLA, E. L; MIZUBUTI, I. Y.; SILVA, L. D. F.; REEVES, J. J. Desempenho e características de carcaça de bovinos de diferentes grupos genéticos. Revista Brasileira de Zootecnia, v. 37, n. 9, p. 1.669-1.673, 2008. Disponível em: <http://www.scielo.br/scielo.php?pid=S1516$-35982008000900020 \&$ script $=$ sci_abstract\&tlng=pt $>$. Acesso em: 20 mar. 2010.

ROCHA JR. V. R.; SILVA, F. V.; BARROS, R. C.; REIS, S. T.; COSTA, M. D.; SOUZA, A. S.; CALDEIRA, L. A.; OLIVEIRA, T. S.; OLIVEIRA, L. L. S. Desempenho e características de carcaça de bovinos nelore e mestiços terminados em confinamento. Revista Brasileira de Saúde e Produção Animal, v. 11, n. 3, p. 865-875, 2010.

SAS Program. User guide for personal computer. Cary, North Caroline: SAS, 2002.

TAROUCO, J. U. LOBATO, J.; PIVA, F.; TAROUCO, A. K.; MASSIA, G. S. Relação entre medidas ultra-sônicas e espessura de gordura subcutânea ou área de olho de lombo na carcaça em bovinos de corte. Revista Brasileira de Zootecnia, v. 34, n. 6, p. 2.074-2.084, 2005. Disponível em: <http:/www.scielo.br/scielo. php?script $=$ sci_arttext\&pid=S1516-35982005000600033 $>$. Acesso em: 25 mar. 2010.

VALADARES FILHO, S. C.; PAULINO, P. V. R.; MAGALHÃES, $K$. A. Exigências nutricionais de zebuínos e tabelas de composição de alimentos BR-corte. 1. ed. Viçosa: Universidade Federal de Viçosa, 2006. 142 p.

VARGAS, L. H.; LANA, R. P.; JHAM, G. N.; SANTOS, F. L.; QUEIROZ, A. C.; MANCIO, A. B. Adição de lipídios na ração de vacas leiteiras: parâmetros fermentativos ruminais, produção e composição do leite. Revista Brasileira de Zootecnia, v. 31, n. 1, p. 522-529, 2002. 